\title{
Papers
}

\section{Using fetal nuchal translucency to screen for major congenital cardiac defects at 10-14 weeks of gestation: population based cohort study}

Jon Hyett, Marc Perdu, Gurleen Sharland, Rosalinde Snijders, Kypros H Nicolaides

\begin{abstract}
Objectives To examine the utility of measuring fetal nuchal translucency thickness in screening for major defects of the heart and great arteries at 10-14 weeks of gestation.

Design Population based cohort study.

Subjects 29154 singleton pregnancies with chromosomally normal fetuses at 10-14 weeks of gestation.

Setting Fetal medicine centre in London.

Main outcome measure Prevalence of major defects of the heart and great arteries.

Results Of 50 cases with major defects of the heart and great arteries (prevalence 1.7 per 1000 pregnancies) 28 ( $56 \%, 95 \%$ confidence interval $42 \%$ to $70 \%$ ) were in the subgroup of 1822 pregnancies with fetal nuchal translucency thicknesses above the 95th centile of the normal range. The positive and negative predictive values for this cut off point of nuchal translucency thickness were $1.5 \%$ and $99.9 \%$ respectively.

Conclusions Measurement of fetal nuchal translucency thickness-traditionally used to identify fetuses at high risk of aneuploidy-at 10-14 weeks of gestation can identify a large proportion of fetuses with major defects of the heart and great arteries.
\end{abstract}

\section{Introduction}

Cardiac defects are the most common congenital abnormalities. The prevalence is 3-8 per 1000 pregnancies. ${ }^{2}$ In the United Kingdom, studies on screening women with low risk pregnancies by ultrasonography showed a prevalence of congenital abnormalities of 1.33.2 per 1000 pregnancies. ${ }^{34}$ About half of these defects are asymptomatic, and the other half are classed as major because they are either lethal or require surgery. Specialist fetal echocardiography at around 20 weeks of gestation can identify most of the major cardiac defects,${ }^{5}$ but the main challenge in prenatal diagnosis is to identify those pregnancies at high risk that need referral to specialist centres. Currently, screening is based on examination of the four chamber view of the heart during routine ultrasonography at 16-22 weeks of gestation, but a recent study of 7459 pregnancies showed that an abnormal four chamber view can identify only $26 \%$ of major cardiac defects. ${ }^{7}$
A more sensitive method of screening may potentially be the ultrasonographic measurement of fetal nuchal translucency thickness at 10-14 weeks of gestation. $^{8}$ Extensive studies have recently shown a strong association between cardiac defects and increased nuchal translucency thickness, which is thought to be the result of subcutaneous oedema in the nuchal region. ${ }^{9-11}$ In four studies reporting on a total of 21 fetuses with major cardiac defects diagnosed at
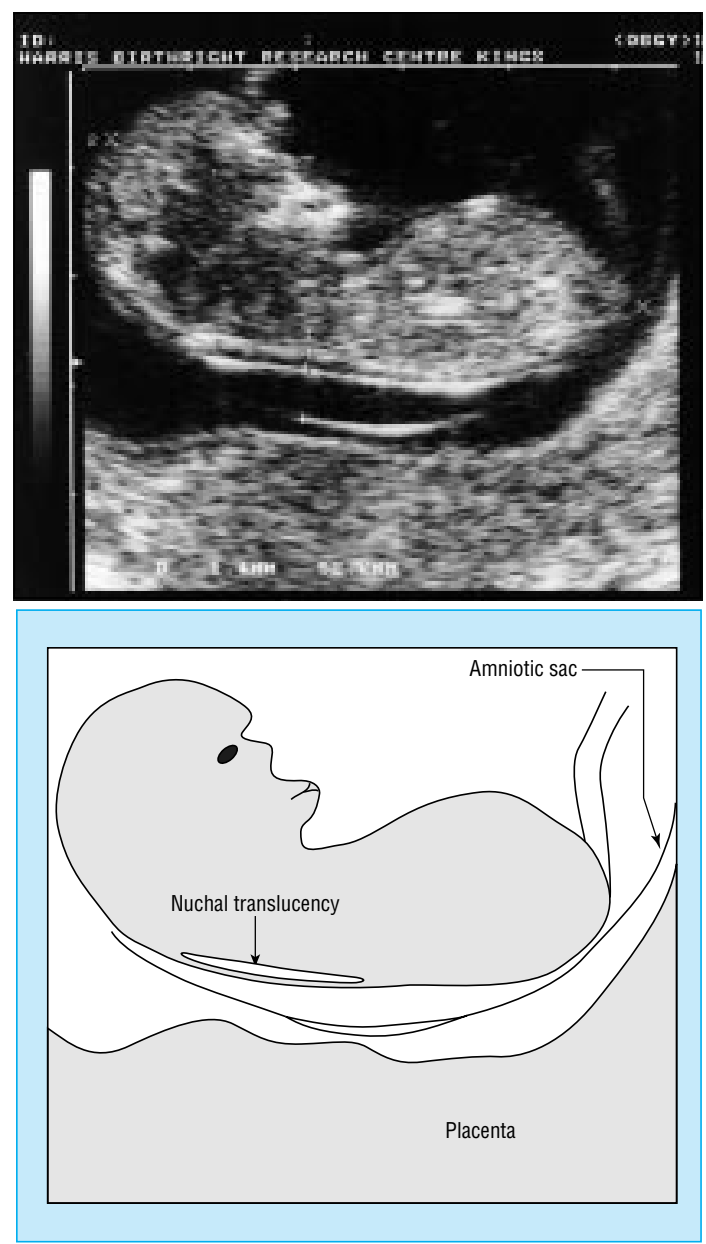

Fig 1 Ultrasonogram of 11 week old fetus showing measurement of crown-rump length and fetal nuchal translucency thickness
Editorial by Mol

Harris Birthright Research Centre for Fetal Medicine,

Department of Obstetrics and

Gynaecology, King's College Hospital Medical School, London SE5 8RX Jon Hyett, research fellow

Marc Perdu, research fellow Rosalinde Snijders, lecturer

Kypros Nicolaides, professor

Fetal Cardiology Unit, Guy's Hospital, London SE1 9RT

Gurleen Sharland, senior lecturer

Correspondence to: Professor

Nicolaides

BMJ 1999;318:81-5 


\begin{tabular}{|c|c|c|c|c|}
\hline Case & $\begin{array}{l}\text { Nuchal } \\
\text { translucency } \\
\text { thickness } \\
(\mathrm{mm})\end{array}$ & $\begin{array}{c}\text { Diagnosis } \\
\text { (weeks) }\end{array}$ & Outcome & Major abnormality of heart and great arteries \\
\hline 1 & 1.0 & 18 & Termination & $\begin{array}{l}\text { Ventricular septal defect, presented with congenital } \\
\text { heart block }\end{array}$ \\
\hline 2 & 1.2 & 31 & Termination & Ebstein's anomaly with pulmonary stenosis \\
\hline 3 & $4.0^{*}$ & 12 & Termination & Exocardia \\
\hline 4 & 1.8 & 20 & Termination & Tetralogy of Fallot \\
\hline 5 & 2.1 & 20 & Termination & $\begin{array}{l}\text { Hypoplastic left heart with double outlet right } \\
\text { ventricle, asymmetrical pulmonary valve }\end{array}$ \\
\hline 6 & $2.3 \dagger$ & 20 & Termination & Atrioventricular septal defect \\
\hline 7 & $2.7 \dagger$ & 16 & Termination & Hypoplastic left heart syndrome \\
\hline 8 & $3.5^{*}$ & 19 & Termination & Tetralogy of Fallot \\
\hline 9 & $4.0^{*}$ & 18 & Termination & $\begin{array}{l}\text { Mitral atresia, ventricular septal defect, double } \\
\text { outlet right ventricle }\end{array}$ \\
\hline 10 & $3.6^{*}$ & 21 & Termination & Hypoplastic left heart syndrome \\
\hline 11 & $5.0^{*}$ & 24 & Termination & $\begin{array}{l}\text { Hypoplastic right ventricle, atresia of tricuspid valve, } \\
\text { ventricular septal defect, hypoplastic ductus } \\
\text { arteriosus, right subclavian arterial ring }\end{array}$ \\
\hline 12 & $5.5^{\star}$ & 18 & Termination & $\begin{array}{l}\text { Aortic atresia and atrioventricular septal defect to } \\
\text { dominant right ventricle }\end{array}$ \\
\hline 13 & 1.8 & 25 & Postnatal deathł & Atrioventricular septal defect \\
\hline 14 & 2.2 & 30 & Postnatal death & Ventricular septal defect requiring surgery \\
\hline 15 & $2.7 \dagger$ & 20 & Live birth & Ventricular septal defect requiring surgery \\
\hline 16 & $2.8 \dagger$ & 20 & Live birth & $\begin{array}{l}\text { Coarctation of the aorta, ventricular septal defect; } \\
\text { arch repaired surgically }\end{array}$ \\
\hline 17 & $4.5^{*}$ & 18 & Live birth & Transposition of great arteries \\
\hline 18 & $4.0^{\star}$ & 21 & Live birth & $\begin{array}{l}\text { Transposition of great arteries, pulmonary stenosis, } \\
\text { dextrocardia }\end{array}$ \\
\hline
\end{tabular}

${ }^{*}$ Thickness greater than 99th centile for gestational age. $†$ Thickness greater than 95th centile for gestational age. ‡Death occurred after surgery for cardiac abnormality.

Table 2 Major defects of heart and great arteries diagnosed at postmortem examination after termination of pregnancy for extracardiac defects or intrauterine death

\begin{tabular}{|c|c|c|c|}
\hline Case & $\begin{array}{l}\text { Nuchal } \\
\text { ranslucency } \\
\text { thickness } \\
(\mathrm{mm})\end{array}$ & Outcome & Pathological findings \\
\hline 19 & $3.0^{*}$ & $\begin{array}{l}\text { Termination at } 13 \text { weeks for limb } \\
\text { abnormalities }\end{array}$ & $\begin{array}{l}\text { Coarctation of the aorta, ventricular septal } \\
\text { defect, bicuspid aortic valve }\end{array}$ \\
\hline 20 & $4.7 \dagger$ & $\begin{array}{l}\text { Termination at } 23 \text { weeks for Smith } \\
\text { Lemli Opitz syndrome }\end{array}$ & Hypoplastic right ventricle \\
\hline 21 & $9.0 \dagger$ & $\begin{array}{l}\text { Termination at } 13 \text { weeks for } \\
\text { exomphalos }\end{array}$ & Hypoplastic pulmonary trunk \\
\hline 22 & $14.0 \dagger$ & Termination at 15 weeks for hydrops & Interrupted aortic arch, ventricular septal defect \\
\hline 23 & 1.7 & Intrauterine death at 37 weeks & $\begin{array}{l}\text { Premature closure of foramen ovale with } \\
\text { associated left heart hypoplasia }\end{array}$ \\
\hline 24 & 1.7 & Intrauterine death at 20 weeks & $\begin{array}{l}\text { Univentricular heart, absent tricuspid valve, } \\
\text { pulmonary trunk arising from right atrium }\end{array}$ \\
\hline 25 & 1.9 & Intrauterine death at 28 weeks & Truncus arteriosus \\
\hline 26 & $4.9+$ & Intrauterine death at 13 weeks & Coarctation of aorta \\
\hline 27 & $6.0 \dagger$ & Intrauterine death at 13 weeks & $\begin{array}{l}\text { Coarctation of aorta, perimembranous } \\
\text { ventricular septal defect }\end{array}$ \\
\hline 28 & $8.0 \dagger$ & Intrauterine death at 13 weeks & $\begin{array}{l}\text { Narrow ascending aorta and aortic isthmus, } \\
\text { imperforate aortic valve, dilated pulmonary } \\
\text { trunk, ductus arteriosus }\end{array}$ \\
\hline 29 & $8.2 \dagger$ & Intrauterine death at 14 weeks & Coarctation of aorta, ventricular septal defect \\
\hline 30 & $9.4 \dagger$ & Intrauterine death at 16 weeks & Coarctation of aorta \\
\hline 31 & $11.0 \dagger$ & Intrauterine death at 15 weeks & Coarctation of aorta \\
\hline
\end{tabular}

10-14 weeks of gestation, $17(81 \%)$ had increased nuchal translucency thickness. ${ }^{12-15}$ In addition, pathological studies of both chromosomally abnormal and normal fetuses with increased nuchal translucency thickness have shown a high prevalence of abnormalities of the heart and great arteries. ${ }^{16}{ }^{17}$ Furthermore, a study of 1389 chromosomally normal fetuses with increased nuchal translucency thickness reported that the prevalence of major cardiac defects increased exponentially with nuchal translucency thickness. ${ }^{18}$
Our study of 29154 singleton pregnancies, presumed to be chromosomally normal, examined the utility of measuring fetal nuchal translucency thickness at 10-14 weeks of gestation as a method of screening for major abnormalities of the heart and great arteries.

\section{Subjects and methods}

We undertook a retrospective study to examine the prevalence of major cardiac defects in a population of 31162 singleton pregnancies. The pregnancies were screened for chromosomal abnormalities by a combination of maternal age and fetal nuchal translucency thickness at 10-14 weeks of gestation.

The fetal crown-rump length and nuchal translucency thickness (fig 1) were measured as previously described by transabdominal ultrasonography, unless visualisation was poor in which case vaginal ultrasonography was carried out. ${ }^{8}$ Demographic details and ultrasound findings including number of fetuses, crown-rump length, and nuchal translucency thickness were entered into a computer database at the time of scanning. Karyotype results and details on pregnancy outcome were added as soon as these became available. Pregnancy outcome was obtained from maternity units, general practitioners, or the patients; the patients were given a questionnaire at the time of the initial scan. If no outcome data were received within two months of the expected date of delivery, we contacted the patients by telephone.

A computer search identified all singleton pregnancies with live fetuses at 10-14 weeks of gestation with a crown-rump length of $38-84 \mathrm{~mm}$ and an estimated date of delivery before 1 June 1997. The database was then searched for major abnormalities of the heart and great arteries, diagnosed before or after birth, in the group with a normal fetal karyotype or the birth of a baby with no dysmorphic features suggestive of a chromosomal abnormality.

The prevalence of major cardiac defects was determined and the utility of screening for nuchal translucency thickness including sensitivity, specificity, and positive and negative predictive values were calculated for the nuchal translucency thickness cut off points of the 95th and 99th centiles for crown-rump length. Nuchal translucency thickness normally increases with crown-rump length, and the 95th centile is $2.2 \mathrm{~mm}$ for a crown-rump length of $38 \mathrm{~mm}$ and $2.8 \mathrm{~mm}$ for a crown-rump length of $84 \mathrm{~mm}$; the 99th centile does not change significantly with crown-rump length and is about $3.5 \mathrm{~mm} .{ }^{9}$

\section{Results}

Our study group comprised 31162 pregnancies. We excluded from further analysis 323 pregnancies with chromosomal abnormalities, 317 pregnancies with spontaneous miscarriages, and 1368 pregnancies where the women had changed address and despite repeated attempts through their general practitioners and maternity hospitals, it was impossible to obtain information on pregnancy outcome. In the remaining 29154 pregnancies the median gestation at the time of screening was 12 weeks (range 10-14 weeks) and the median maternal age was 34 years (range 15 - 48 years). The fetal nuchal translucency thickness was above the 
95th centile for crown-rump length in 1822 (6.3\%) pregnancies and above the 99th centile in $315(1.1 \%)$ pregnancies.

Major defects of the heart and great arteries were identified in 50 of the pregnancies. These included 18 pregnancies that were diagnosed antenatally by ultrasonography at 16-31 weeks of gestation (table 1), 13 that were diagnosed at pathological examination after intrauterine death or termination of pregnancy for conditions other than cardiac defects (table 2), and 19 that were diagnosed in live births (table 3).

The prevalence of major cardiac defects was 1.7 per 1000 pregnancies (50/29 154), which increased with nuchal translucency thickness from 0.8 per 1000 for those pregnancies with nuchal translucency thickness below the 95th centile to 63.5 per 1000 for those pregnancies with nuchal translucency thickness above the 99th centile (table 4). There were essentially six groups of cardiac defects; tetralogy of Fallot, hypoplastic left heart, transposition of the great arteries, coarctation of the aorta and aortic stenosis or atresia, ventricular and atrioventricular septal defects, and a sixth group of other complex defects (table 5). Table 6 shows the sensitivity, specificity, and positive and negative predictive values of nuchal translucency thickness cut off points of the 95th and 99th centiles in the detection of major cardiac defects, and figure 2 shows a receiver-operator characteristic curve.

Table 3 Major defects of heart and great arteries diagnosed postnatally

\begin{tabular}{lll} 
Case & $\begin{array}{c}\text { Nuchal } \\
\text { translucency } \\
\text { thickness } \\
(\mathbf{m m})\end{array}$ & Major abnormality of heart and great vessels \\
\hline 32 & 1.0 & Tetralogy of Fallot \\
\hline 33 & 1.5 & Large ventricular septal defect \\
\hline 34 & 1.5 & Total anomalous pulmonary drainage \\
\hline 35 & 1.6 & Tetralogy of Fallot \\
\hline 36 & 1.7 & Tetralogy of Fallot \\
\hline 37 & 1.7 & Transposition of great arteries \\
\hline 38 & 1.8 & Transposition of great arteries, ventricular septal defect \\
\hline 39 & 1.9 & Tetralogy of Fallot \\
\hline 40 & 1.9 & Transposition of great arteries \\
\hline 41 & 2.0 & Transposition of great arteries, ventricular septal defect \\
\hline 42 & 2.2 & Tetralogy of Fallot \\
\hline 43 & 2.2 & Tetralogy of Fallot \\
\hline 44 & 2.3 & Ebstein's anomaly \\
\hline 45 & $2.3^{*}$ & Transposition of great arteries \\
\hline 46 & $3.0^{*}$ & Large ventricular and atrial septal defect \\
\hline 47 & $3.0^{*}$ & $\begin{array}{l}\text { Ventricular septal defect, double outlet right ventricle, } \\
\text { pulmonary stenosis }\end{array}$ \\
\hline 48 & $3.5 \dagger$ & Tetralogy of Fallot \\
\hline 49 & $3.8 \dagger$ & Large ventricular septal defect \\
\hline 50 & $4.5 \dagger$ & Transposition of great arteries \\
\hline${ }^{*}$ Thickness greater than 95 th centile for gestational age. \\
\hline Thickness greater than 99th centile for gestational age. \\
\hline
\end{tabular}

Table 4 Prevalence of major defects of heart and great arteries in fetuses that were chromosomally normal

\begin{tabular}{lrcc}
$\begin{array}{l}\text { Nuchal translucency } \\
\text { thickness }\end{array}$ & $\begin{array}{c}\text { No of } \\
\text { fetuses }\end{array}$ & $\begin{array}{c}\text { No of major } \\
\text { cardiac defects }\end{array}$ & $\begin{array}{c}\text { Prevalence per } \\
\text { 1000 fetuses }\end{array}$ \\
\hline$<95$ th centile & 27332 & 22 & 0.8 \\
\hline$\geqslant 95$ th centile-3.4 mm & 1507 & 8 & 5.3 \\
\hline $3.5-4.4 \mathrm{~mm}$ & 208 & 6 & 28.9 \\
\hline $4.5-5.4 \mathrm{~mm}$ & 66 & 6 & 90.9 \\
\hline$\geqslant 5.5 \mathrm{~mm}$ & 41 & 8 & 195.1 \\
\hline Total & 29154 & 50 & 1.7 \\
\hline
\end{tabular}

Table 5 Detection of specific cardiac defects using increased fetal nuchal translucency thickness

\begin{tabular}{lccc} 
& & \multicolumn{2}{c}{ Nuchal translucency } \\
\cline { 3 - 4 } Cardiac defect & No (\%) & No (\%) & No (\%) \\
\hline of fetuses & $>95$ th centile & $>$ 99th centile \\
\hline Hypoplastic left heart & $9(18)$ & $2(22)$ & $2(22)$ \\
\hline Transposition of great arteries & $3(6)$ & $2(67)$ & $1(33)$ \\
\hline Coarctation of aorta, aortic stenosis, or atresia & $8(16)$ & $4(50)$ & $3(38)$ \\
\hline Ventricular and atrioventricular septal defects & $10(20)$ & $10(100)$ & $8(80)$ \\
\hline Other defects & $8(16)$ & $4(50)$ & $1(13)$ \\
\hline Total & $12(24)$ & $6(50)$ & $5(42)$ \\
\hline
\end{tabular}

Table 6 Sensitivity and specificity of screening for major defects of heart and great arteries using fetal nuchal translucency thickness. Values are percentages (95\% confidence intervals)

\begin{tabular}{lcc} 
& Using 95th centile & Using 99th centile \\
\hline Sensitivity & $56.0(42.0$ to 70.0$)$ & $40.0(26.0$ to 54.0$)$ \\
\hline Specificity & $93.8(93.6$ to 94.1$)$ & $99.0(98.9$ to 99.1$)$ \\
\hline Positive predictive value & $1.5(1.0$ to 2.1$)$ & $6.3(3.7$ to 9.0$)$ \\
\hline Negative predictive value & $99.9(99.8$ to 100.0$)$ & $99.9(99.8$ to 100.0$)$ \\
\hline
\end{tabular}

\section{Discussion}

Our study shows that $55 \%$ of major abnormalities of the heart and great arteries are associated with increased fetal nuchal translucency thickness at 10-14 weeks of gestation. This method of screening compares favourably with the reported sensitivity of $26 \%$ using the four chamber view of the heart at 16-22 weeks of gestation. The clinical implication of our findings is that increased nuchal translucency thickness constitutes an indication for specialist fetal echocardiography. Certainly the overall prevalence of major cardiac defects in such a group of fetuses (about 2\%) is similar to that found in pregnancies affected by maternal diabetes mellitus or with a history of a previously affected offspring, which are well accepted indications for fetal echocardiography. ${ }^{19} 20$

At present there may be insufficient facilities for specialist fetal echocardiography to accommodate the potential increase in demand if the 95th centile of nuchal translucency thickness is used as the cut off point for referral. In contrast, a cut off point of the 99th centile would result in only a small increase in workload, and in this population the prevalence of major cardiac defects would be very high.

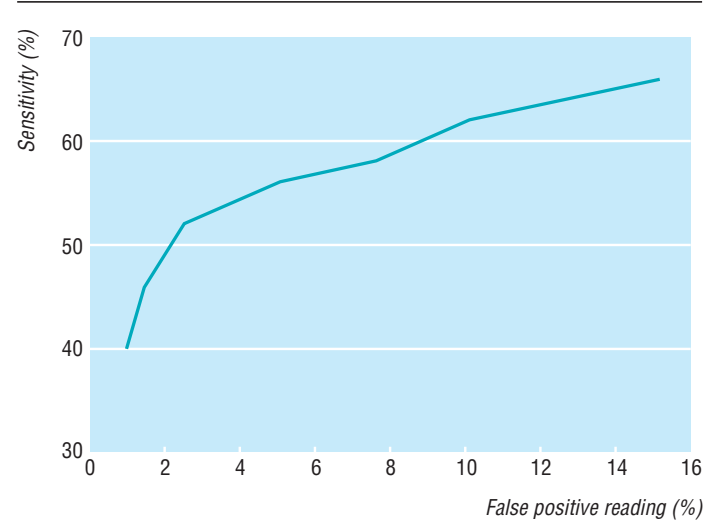

Fig 2 Receiver-operator characteristic curve showing detection rate for major cardiac defects at various false positive rates with increased nuchal translucency thickness 
The consequence of combining data from terminations of pregnancy and intrauterine deaths with data from live births would be an overestimate of the true prevalence of cardiac defects in live births from a non-selected population; a proportion of cardiac defects diagnosed antenatally would have resulted in intrauterine death. However, the opportunity to determine such prevalence in "undisturbed" populations was lost in the early 1970 s with the advent of prenatal diagnosis. In any case, as shown in the group of patients where the parents chose to continue with the pregnancy after the prenatal diagnosis of major cardiac defects, although the defect obviously persists throughout pregnancy, increased nuchal translucency thickness observed at 10-14 weeks of gestation often resolves by the second trimester and the babies are born alive. Similarly, information on intrauterine deaths is important both for offering a possible explanation for the death and in defining the risk of recurrence. This risk rises from $2 \%$ to $10 \%$ if there are two rather than one previously affected offspring, and the recurrence is frequently of the same severity or greater severity as the index case. ${ }^{20}$

The prevalence of major cardiac defects in our population (1.8 per 1000 pregnancies) of presumed chromosomally normal fetuses is compatible with the previously reported prevalence for all cardiac defects in live births (3-8 per 1000 pregnancies); the higher prevalence was reported in studies using echocardiography for diagnosing lesions that are asymptomatic, minor, and even without murmurs. Our study did not include detailed cardiological assessment of all neonates, and since many of the asymptomatic defects would inevitably have been missed, we used major defects as the outcome measure. In contrast to previous studies, our population was confined to those pregnancies presumed to be chromosomally normal; about $25 \%$ of affected individuals are chromosomally abnormal. Another factor that may have underestimated our birth prevalence of cardiac defects is the short interval between delivery and obtaining outcome data (in most cases within one month); previous studies have reported that only about $60 \%$ of congenital cardiac defects are diagnosed by one month after birth. ${ }^{4}$

The distribution of different types of cardiac defects in our study (table 6) is similar to that described in previous prenatal and postnatal series.. ${ }^{3} 72122$ Although increased nuchal translucency thickness was observed with all types of major abnormalities of the heart and great arteries, there was a stronger association with left sided defects such as hypoplastic left heart and coarctation of the aorta.

Pregnancies identified by nuchal translucency scanning as being at high risk of cardiac defects need not wait until 20 weeks for specialist echocardiography. Improvements in the resolution of ultrasound machines have made it possible to undertake detailed cardiac scanning in the first trimester of pregnancy. ${ }^{13}{ }^{23-25}$ Furthermore there are several case reports or small series on the ultrasonographic diagnosis of cardiac defects at 10-14 weeks of gestation, and it is interesting that in 21 fetuses with major cardiac defects, 17 (81\%) had increased nuchal translucency thickness. ${ }^{12-15}$
- The majority of congenital abnormalities of the heart and great arteries are associated with subcutaneous oedema in the neck region at 10-14 weeks of gestation

- Subcutaneous oedema in the neck region can be visualised by ultrasonography as increased nuchal translucency thickness

- The prevalence of major defects of the heart and great arteries increases with increasing fetal nuchal translucency thickness at 10-14 weeks of gestation

- Measurement of fetal nuchal translucency thickness at 10-14 weeks of gestation is a sensitive method of screening for major defects of the heart and great arteries

Measurement of fetal nuchal translucency thickness at 10-14 weeks of gestation-traditionally used to identify fetuses at high risk of aneuploidy ${ }^{26}$-also identifies the majority of pregnancies with major defects of the heart and great arteries.

Contributors: JH, MP, GS, RS, and KHN contributed to the planning and execution of the study and the writing of the paper; $\mathrm{KHN}$ will act as guarantor for the paper.

Funding: Fetal Medicine Foundation.

Conflict of interest: None.

1 Ferencz C, Rubin JD, McCarter RJ, Brenner JI, Neill CA, Perry LW. Congenital heart disease: prevalence at livebirth. The Baltimore-Washington infant study. Am J Epidemiol 1985;121:31-6.

2 Hoffman JIE. Incidence of congenital heart disease: I. Postnatal incidence. Pediatr Cardiol 1995;16:103-13.

3 Chitty LS, Hunt GH, Moore J, Lobb MO. Effectiveness of routine ultrasonography in detecting fetal structural anomalies in a low risk population. BMJ 1991;303:1165-9.

4 Luck CA. Value of routine ultrasound scanning at 19 weeks: a four year study of 8849 deliveries. BMJ 1992;304:1474-8.

5 Allan LD, Crawford DC, Anderson RH, Tynan MJ. Echocardiographic and anatomical correlations in fetal congenital heart disease. Br Heart J 1984;52:542-8.

6 Copel JA, Pilu G, Green J, Hobbins JC, Kleinman CS. Fetal echocardiographic screening for congenital heart disease: the importance of the four-chamber view. Am J Obstet Gynecol 1987;157:648-55.

7 Tegnander E, Eik-Ness SH, Johansen OJ, Linker DT. Prenatal detection of heart defects at the routine fetal examination at 18 weeks in a heart defects at the routine fetal examination at 18 weeks

8 Nicolaides KH, Azar G, Byrne D, Mansur C, Marks K. Fetal nuchal translucency: ultrasound screening for chromosomal defects in first trimester of pregnancy. BMJ 1992;304:867-9

9 Pandya PP, Snijders RJM, Johnson SP, Brizot ML, Nicolaides KH. Screening for fetal trisomies by maternal age and fetal nuchal translucency thickness at 10-14 weeks of gestation. Br J Obstet Gynaecol 1995;102: 957-62.

10 Snijders RJM, Johnson S, Sebire NJ, Noble PL, Nicolaides KH. First-trimester ultrasound screening for chromosomal defects. Ultrasound Obstet Gynecol 1996; 7:216-26.

11 Taipale P, Hiilesmaa V, Salonen R, Ylostalo P. Increased nuchal translucency as a marker for fetal chromosomal defects. $N$ Engl J Med $1997 ; 337: 1654-8$

12 Gembruch U, Knopfle G, Chatterjee M, Bald R, Hansmann M. First-trimester diagnosis of fetal congenital heart disease by transvaginal two-dimensional and Doppler echocardiography. Obstet Gynecol 1990-dimensional

13 Gembruch U, Knopfle G, Bald R, Hansmann M. Early diagnosis of fetal congenital heart disease by transvaginal echocardiography. Ultrasound Obstet Gynecol 1993;3:310-7.

14 Bronshtein M, Siegler E, Yoffe N, Zimmer EZ. Prenatal diagnosis of ventricular septal defect and overriding aorta at 14 weeks' gestation, using transvaginal sonography. Prenat Diagn 1990;10:697-702.

15 Achiron R, Rotstein Z, Lipitz S, Mashiach S, Hegesh J. First-trimester diagnosis of fetal congenital heart disease by transvaginal ultrasonography. Obstet Gynecol 1994;84:69-72.

16 Hyett JA, Moscoso G, Nicolaides KH. Abnormalities of the heart and great arteries in first trimester chromosomally abnormal fetuses. $\mathrm{Am} \mathrm{J}$ Med Genet 1997;69:207-16.

17 Hyett J, Moscoso G, Papapanagiotou G, Perdu M, Nicolaides K. Abnormalities of the heart and great vessels in chromosomally normal 
fetuses with increased nuchal translucency thickness at 10-13 weeks of gestation. Ultrasound Obstet Gynecol 1996;7:245-50.

18 Hyett JA, Perdu M, Sharland GK, Snijders RJM, Nicolaides KH. Increased nuchal translucency at 10-14 weeks of gestation as a marker for major cardiac defects. Ultrasound Obstet Gynecol 1997;10:242-6.

19 Meyers-Wittkopt M, Simpson JM, Sharland GK. Incidence of congenital heart disease in fetuses of diabetic mothers-a retrospective study of 326 cases. Ultrasound Obstet Gynecol 1996;8:8-10

20 Allan LD, Crawford DC, Chita SK, Anderson RH, Tynan MJ. Familia recurrence of congenital heart disease in a prospective series of mothers referred for fetal echocardiography. Am J Cardiol 1996;58:334-7.

21 Rustico MA, Benettoni A, D'Ottavio G, Maieron A, Fischer-Tamaro I, Conoscenti G, et al. Fetal heart screening in low-risk pregnancies. Ultrasound Obstet Gynecol 1995;6:313-9.
22 Mitchell SC, Korones SB. Congenital heart disease in 56,109 births. Incidence and natural history. Circulation 1971;43:323-33.

23 Dolkart LA, Reimers FT. Transvaginal fetal echocardiography in early pregnancy: normative data. Am J Obstet Gynecol 1991;165:688-91.

24 Carvahlo JS, Moscoso G, Ville Y. First trimester transabdominal fetal echocardiography. Lancet 1998;351:1023-7.

25 Sharland G. First trimester transabdominal fetal echocardiography Lancet 1998;351:1662.

26 Snijders RJM, Noble P, Sebire N, Souka A, Nicolaides KH. UK multicentre project on assessment of risk of trisomy 21 by maternal age and fetal nuchal translucency thickness at 10-14 weeks of gestation. Lance $1998 ; 352: 343-6$.

(Accepted 27 August 1998)

\section{Science commentary: What is fetal nuchal translucency?}

In the fetus fluid collects behind the neck, much like it does in dependent ankle oedema in later life. This occurs partly because of the fetus's tendency to lie on its back and partly because of the laxity of the skin of the neck. As with ankle oedema this accumulation of fluid can represent the end point of several pathological processes, including heart failure. Fluid collecting behind the neck can be detected as nuchal translucency by ultrasound scanning, and it can be measured. The more fluid that has accumulated, the greater the risk of an abnormality being present.

Chromosomal abnormalities-for example, Down's syndrome-can cause fluid accumulation. Chromosome 21 contains the gene that codes for type VI collagen. In trisomy 21 one subunit of this collagen can be overexpressed, resulting in connective tissue that has a more elastic composition.

Failure of fetal movements is also likely to cause nuchal thickening. Neuromuscular abnormalities can cause poor breathing and body movements, both of which may lead to fluid collecting as happens in peripheral oedema. One example is arthrogryposis, which causes contractures and flexion deformities and can be fatal. Other causes are intrathoracic and extrathoracic compressive syndromes. If the thoracic cage is abnormally narrow or an intrathoracic lesion is present (such as a diaphragmatic hernia) the vessels in the fetus's head and neck become congested and oedema occurs. Likewise, if heart failure occurs (due to congenital cardiac abnormalities or cardiac dysfunction) more extravascular fluid will form.

There is a brief opportunity between 10 and 14 weeks' gestation (when the fetal lymphatic system is developing and the peripheral resistance of the placenta is high) to detect abnormal fluid collections. After 14 weeks the lymphatic system is likely to have developed sufficiently to drain away any excess fluid, and changes to the placental circulation will result in a drop in peripheral resistance. So after this time any abnormalities causing fluid accumulation may seem to correct themselves and can thus go undetected by measuring nuchal translucency.

About $90 \%$ of fetuses with a nuchal translucency measurement of $3 \mathrm{~mm}$ ("high") at 12 weeks' gestation are normal at birth, while $10 \%$ have major abnormalities. Only $10 \%$ of babies with a measurement of $6 \mathrm{~mm}$ ("very high") at this time will be found to be normal. In centres that perform nuchal translucency measurements, once a fetus has been identified as having a high nuchal translucency, mothers are usually offered chorionic villus sampling and a repeat scan about two weeks later to exclude chromosomal or major physical abnormalities.

Abi Berger, Science editor, BMJ

\section{One hundred years ago \\ Special correspondence: Rome}

Since Christmas the annual university disorders have recurred in Italy. This year they began in the University of Palermo, where the students were desirous of obtaining an additional session of examinations. Professor Baccelli, the Minister of Public Instruction, refused to grant the request and threatened to close the University for the academic year if they did not cease the disorders, which had also extended to the University of Naples. This firm action soon put a stop to the disturbances in both Universities. Later the students attending the anatomical school of the University of Turin, by way of protest against the appointment of Dr. Fusari to the Chair of Human Anatomy, made such disturbances that it was impossible for him to continue his lectures. The Rector of the University published a manifesto, with the sanction of Professor Baccelli, in which he stated that the school of anatomy would not be reopened until the students pledged themselves in writing that order would be kept at Professor Fusari's lectures. If the students did not agree to this, the school would be closed for the whole year, and the summer and autumn examinations would not be held. On February 24th the course was reopened for those students who had complied with the Rector's demand. While these students were entering the school the anti-Fusarians tried to prevent them, crying out "Tutti o nessuno?" The latter were dispersed by the police, and they went to the University, where they tried in vain to get the support of the students of the other faculties. On February 26th they endeavoured forcibly to enter the school of anatomy, and came into collision with the public authorities. Many of them were arrested, and they are now being tried in Turin. The Academic Council then decreed the closure of the course of anatomy for the current year. Why the students object to Professor Fusari is not very clear, as he is a very able man, has had a distinguished university career, and has the warm support of all his colleagues. The firm action of Professor Baccelli in reference to these disorders has been warmly praised in the Chamber of Deputies and by the press. (BMJ 1899;i:629) 